\title{
Effect of renal function on pemetrexed-induced haematotoxicity
}

\author{
Yosuke Ando $^{1}$ - Takahiro Hayashi ${ }^{1} \cdot$ Moeko Ujita $^{2} \cdot$ Sumie Murai $^{2} \cdot$ Hideki Ohta $^{1}$. \\ Kaori Ito ${ }^{3} \cdot$ Teppei Yamaguchi $^{4} \cdot$ Minori Funatsu $^{2} \cdot$ Yoshiaki Ikeda $^{2} \cdot$ \\ Kazuyoshi Imaizumi $^{4} \cdot \operatorname{Kenji~Kawada~}^{5} \cdot \operatorname{Kimio~Yasuda}^{2} \cdot$ Shigeki Yamada $^{1}$
}

Received: 6 May 2016 / Accepted: 3 June 2016 / Published online: 10 June 2016

(C) The Author(s) 2016. This article is published with open access at Springerlink.com

\begin{abstract}
Purpose Pemetrexed (PEM) is an anticancer agent used for the treatment of non-small cell lung cancer, malignant pleural mesothelioma and thymoma. Reportedly, PEM has higher efficacy and safety when used in combination with platinum-based agents. However, there are only few reports on the safety of PEM in patients with an eGFR of $\leq 45 \mathrm{~mL} /$ $\mathrm{min}$. We examined the effect of renal function on the safety of regimens containing PEM.

Methods We retrospectively reviewed 221 patients with lung cancer, malignant pleural mesothelioma or thymoma who received treatment with a PEM-containing regimen between 2009 and 2014. Subgroup analyses were performed on the basis of pre-treatment renal function: group A [creatinine clearance (CLcr), $<45 \mathrm{~mL} / \mathrm{min}$ ); group B (CLcr, $45-80 \mathrm{~mL} / \mathrm{min})$; and group C (CLcr, $\geq 80 \mathrm{~mL} / \mathrm{min})$. For the purpose of this analysis, the lowest documented blood cell counts and haemoglobin levels, the highest levels of serum
\end{abstract}

Takahiro Hayashi

taka-h@fujita-hu.ac.jp

1 Department of Clinical Pharmacy, School of Medicine, Fujita Health University, 1-98 Dengakugakubo, Kutsukake-cho, Toyoake 470-1192, Japan

2 College of Pharmacy, Kinjo Gakuin University, 2-1723 Omori, Moriyama, Nagoya 463-8521, Japan

3 Department of Hematology, School of Medicine, Fujita Health University, 1-98 Dengakugakubo, Kutsukake-cho, Toyoake 470-1192, Japan

4 Department of Respiratory Medicine, School of Medicine, Fujita Health University, 1-98 Dengakugakubo, Kutsukake-cho, Toyoake 470-1192, Japan

5 Department of Medical Oncology, School of Medicine, Fujita Health University, 1-98 Dengakugakubo, Kutsukake-cho, Toyoake 470-1192, Japan creatinine, aspartate aminotransferase, alanine aminotransferase and CLcr from the time of initial administration up to prior to the start of second administration were considered. Results Groups A, B and C had 8, 123 and 90 patients, respectively. The incidence of grade 2 thrombocytopaenia was significantly higher in group $\mathrm{A}$ as compared to that in groups $\mathrm{B}(P<0.01)$ and $\mathrm{C}(P<0.05)$. On multivariate analysis, only a CLcr of $<45 \mathrm{~mL} / \mathrm{min}$ was an independent risk factor for thrombocytopaenia of $\geq$ grade 2 .

Conclusion When administering a PEM-containing regimen, thrombocytopaenia of $\geq$ grade 2 is more likely to develop in patients with a CLcr of $<45 \mathrm{~mL} / \mathrm{min}$.

Keywords Pemetrexed - Renal dysfunction · Thrombocytopaenia $\cdot$ Non-small cell lung cancer . Malignant pleural mesothelioma

\section{Introduction}

The advent of new drugs and knowledge has revolutionised the treatment of lung cancer. Using epidermal growth factor receptor (EGFR) tyrosine kinase inhibitors for EGFR gene mutation-positive lung cancer [1-5] and anaplastic lymphoma kinase (ALK) inhibitors for echinoderm microtubuleassociated protein-like 4-ALK translocation-positive lung cancer $[6,7]$ have improved overall survival (OS) in these patients. First-line treatment for stage IV lung cancer not associated with genetic mutations includes the combination of third-generation cytocidal antineoplastic preparations, such as irinotecan (CPT-11), paclitaxel (PTX), gemcitabine (GEM) and vinorelbine (VNR), with platinum-based preparations such as cisplatin (CDDP) and carboplatin (CBDCA) [8]. The specific regimens include CPT-11 + CDDP (IP) [9], PTX + CBDCA (TC) $[10,11]$, GEM + CDDP (GP) [12] 
and VNR + CDDP (NP) [12]. In the four-arm cooperative study [12], these four regimens were comparable in terms of therapeutic efficacy. However, much variability was observed with respect to the side effects. In particular, GP therapy was associated with a lower incidence of neutropaenia of $\geq$ grade 3 and febrile neutropaenia (FN) when compared with the other regimens. Moreover, no treatment-related fatality was observed in patients who received GP. The GP regimen has since been considered the safest regimen among the four regimens. Furthermore, in the JMDB study [13] that compared pemetrexed (PEM) + CDDP [treatment for non-small cell lung cancer (NSCLC)] with GP therapy, the former was associated with significantly longer OS in patients with nonsquamous NSCLC. Moreover, PEM + CDDP therapy was associated with a significantly lower incidence of neutropaenia, thrombocytopaenia of $\geq$ grade 3 and $\mathrm{FN}$, as compared to that associated with GP therapy. Based on these results, the National Comprehensive Cancer Network guidelines recommended PEM + CDDP therapy as the regimen with the highest efficacy and safety for EGFR mutation-negative and ALK translocation-negative stage IV non-squamous NSCLC [8].

However, in a phase I study [14], PEM $\left(500 \mathrm{mg} / \mathrm{m}^{2}\right)$ was shown to be well tolerated in patients with a glomerular filtration rate $($ GFR) $>40 \mathrm{~mL} / \mathrm{min}$. Subsequently, in the JMDB study, PEM was administered to patients with a GFR of $>45 \mathrm{~mL} / \mathrm{min}$, while those with a GFR of $\leq 40 \mathrm{~mL} /$ min continued to be excluded. Owing to the lack of definitive evidence on the efficacy and safety of PEM in the latter category of patients, PEM therapy is not recommended for such patients.

PEM plasma clearance is known to correlate with renal function [14]. Furthermore, patients with a GFR of $\leq 45 \mathrm{~mL} / \mathrm{min}$ were shown to have a high incidence of PEM-induced severe neutropaenia $[15,16]$. However, as shown in the JMDB study, PEM + CDDP was shown to have the highest efficacy and safety in patients with NSCLC. Moreover, other recent studies have also suggested the efficacy of PEM monotherapy for NSCLC $[17,18]$.

Therefore, it is necessary to examine tolerance in patients with a GFR of $\leq 45 \mathrm{~mL} / \mathrm{min}$ for lung cancer treatment. Currently, the safety of PEM-containing regimens has not been established for patients with a GFR of $\leq 45 \mathrm{~mL} / \mathrm{min}$, and as evaluation by prospective clinical trials is not ethically permitted, it is relevant first to perform a preliminary retrospective study.

Therefore, we retrospectively analysed data on patients who had received a PEM-containing regimen at our hospital. The objective was to investigate the effect of renal function on the incidence of PEM-induced side effects.

\section{Materials and methods}

\section{Subjects}

Patients treated with a PEM-containing regimen [PEM + CDDP; PEM + CDDP + bevacizumab (Bev); $\mathrm{PEM}+\mathrm{CBDCA} ; \mathrm{PEM}+\mathrm{CBDCA}+\mathrm{Bev} ; \mathrm{PEM}+\mathrm{Bev}$; and PEM monotherapy] for lung cancer, malignant pleural mesothelioma or thymoma at Fujita Health University Hospital between 1 September 2009 and 31 August 2014 were enroled in the study. Patients with renal dysfunction induced by other agents and patients for whom renal function could not be assessed prior to the start of PEM treatment were excluded.

\section{Investigations}

Data were accessed from the electronic medical records available at Fujita Health University Hospital. Renal function investigated prior to the start of treatment was used for the categorisation of patients according to renal function: group A [patients with creatinine clearance (CLcr) of $<45 \mathrm{~mL} / \mathrm{min}$ ], group B (CLcr $45-80 \mathrm{~mL} / \mathrm{min}$ ) and group $\mathrm{C}$ (CLcr $\geq 80 \mathrm{~mL} / \mathrm{min})$. CLcr was calculated from serum creatinine levels using the Cockcroft-Gault equation [19]. The standard method to measure serum creatinine levels is the Jaffe method. However, we used the enzyme method, which is commonly used in Japan, and calculated serum creatinine levels by adding 0.2 to the actual measured values [20, 21].

Data on baseline variables such as age, sex, body surface area and the presence or absence of cancer metastasis and invasion prior to the start of treatment were obtained. Data on the following treatment parameters were obtained: initial dose of pemetrexed $\left(\mathrm{mg} / \mathrm{m}^{2}\right)$, initial dose of cisplatin $\left(\mathrm{mg} / \mathrm{m}^{2}\right)$, initial dose of carboplatin $\left(\mathrm{mg} / \mathrm{m}^{2}\right)$, coadministration of oral folic acid tablets and vitamin $B_{12}$ (because they may help reduce PEM-induced side effects [22-24]) and/or use of non-steroidal anti-inflammatory drugs (NSAIDs) (which can exacerbate PEM-induced side effects $[25,26])$.

\section{Assessment}

The lowest documented values of blood cell counts (leucocyte, neutrophil, red blood cell and platelet counts), haemoglobin and CLcr and the highest levels of serum creatinine, aspartate aminotransferase (AST) and alanine aminotransferase (ALT) were assessed on the basis of the National Cancer Institute-Common Terminology Criteria for Adverse Events version 4.0 (NCI-CTCAE version 4.0). 
Table 1 Patient background (before chemotherapy)

\begin{tabular}{|c|c|c|c|c|}
\hline & $\begin{array}{l}\text { Group A } \\
(n=8)\end{array}$ & $\begin{array}{l}\text { Group B } \\
(n=123)\end{array}$ & $\begin{array}{l}\text { Group C } \\
(n=90)\end{array}$ & $P$ value \\
\hline Age (years) & $72.5(70.5-75.3)$ & $72.0(67.0-76.0)$ & $62.0(57.0-68.8)^{\mathrm{a}, \mathrm{c}}$ & $<0.001$ (Kruskal-Wallis test) \\
\hline Sex (male, female) & 5,3 & 79,44 & 67,23 & $0.363\left(\chi^{2}\right.$ test $)$ \\
\hline CLcr (mL/min) & $38.0(33.7-41.3)$ & $63.3(55.4-73.3)^{\mathrm{b}}$ & $94.3(85.9-102.3)^{\mathrm{b}, \mathrm{c}}$ & $<0.001$ (Kruskal-Wallis test) \\
\hline Cancer classification & & & & $0.827\left(\chi^{2}\right.$ test $)$ \\
\hline Primary tumour & 4 & 69 & 48 & \\
\hline Metastasis or infiltration tumour & 4 & 54 & 42 & \\
\hline Chemotherapy regimen & & & & $0.026\left(\chi^{2}\right.$ test $)$ \\
\hline PEM monotherapy & 1 & 26 & 17 & \\
\hline $\mathrm{PEM}+\mathrm{CDDP}$ & 0 & 36 & 41 & \\
\hline $\mathrm{PEM}+\mathrm{CDDP}+\mathrm{Bev}$ & 0 & 2 & 1 & \\
\hline $\mathrm{PEM}+\mathrm{CBDCA}$ & 7 & 51 & 24 & \\
\hline $\mathrm{PEM}+\mathrm{CBDCA}+\mathrm{Bev}$ & 0 & 8 & 7 & \\
\hline Dosage of PEM $\left(\mathrm{mg} / \mathrm{m}^{2}\right)$ & $432.7 \pm 66.7$ & $488.3 \pm 16.8^{\mathrm{d}}$ & $485.1 \pm 25.3^{\mathrm{d}}$ & $<0.001$ (one-way ANOVA) \\
\hline NSAIDs & 0 & 33 & 36 & $0.013\left(\chi^{2}\right.$ test $)$ \\
\hline
\end{tabular}

$C L c r$ creatinine clearance, $P E M$ pemetrexed, $C D D P$ cisplatin, $C B D C A$ carboplatin, NSAIDs non-steroidal anti-inflammatory drugs

a $P<0.05$ versus group A (Steel-Dwass test)

b $P<0.01$ versus group A (Steel-Dwass test)

c $P<0.01$ versus group B (Steel-Dwass test)

${ }^{\mathrm{d}} P<0.01$ versus group A (Tukey test)

\section{Statistical analysis}

Data on variables with normal distribution are expressed as mean \pm standard deviation. Non-normally distributed variables are expressed as means with interquartile ranges. Between-group differences with respect to normally distributed variables (expressed as frequencies) were assessed using the one-way repeated measures analysis of variance (ANOVA) while non-normally distributed variables were compared using the Kruskal-Wallis test. Data expressed as percentages were assessed by Chi-square test. For multiple comparisons, Bonferroni correction was applied after performing a Chi-square test for two groups. Univariate analysis was performed to identify risk factors. Variables with a significance level of $<20 \%$ were included in the multivariate logistic regression model. Hosmer-Lemeshow statistical test was used to verify goodness of fit. Statistical analyses were performed using SPSS version 22.0 (IBM Corporation, Armonk, NY, USA). Between-group differences associated with a $P$ value of $<0.05$ were considered statistically significant.

\section{Ethics}

The present study was conducted in compliance with the 'ethical guidelines for clinical research'. The study protocol was approved by the 'Ethics committee for epidemiological and clinical research' at our hospital.

\section{Results}

\section{Patients}

The study population consisted of 221 subjects [group A $(n=8)$, group $\mathrm{B}(n=123)$ and group $\mathrm{C}(n=90)]$. All subjects were administered both oral folic acid tablets and vitamin $B_{12}$. A statistically significant difference was observed between the three groups with respect to age, treatment regimen, pemetrexed dose and concurrent use of NSAIDs (Table 1).

\section{Regimen}

Statistically significant differences were observed between the three groups in terms of the usage rate of the CDDPcontaining regimen. On multiple comparisons, the usage rate for group $\mathrm{C}$ was significantly higher than that for group A $(P=0.032)$ and tended to be higher than that for group B $(P=0.056)$. No difference was observed between groups A and $\mathrm{B}(P=0.21)$. Furthermore, between-group differences were observed with respect to the usage rate of CBDCAcontaining regimen. On multiple comparisons, the usage rate for group A was significantly higher than that for group $\mathrm{C}(P=0.0095)$ and tended to be higher than that for group B $(P=0.090)$. No difference was observed between groups $\mathrm{B}$ and $\mathrm{C}(P=0.14)$. There was no difference between the three groups in terms of the usage rate of Bev-containing regimen (Table 2). 
Table 2 Combination chemotherapy regimens containing pemetrexed

\begin{tabular}{lllll}
\hline & $\begin{array}{l}\text { Group A } \\
(n=8)\end{array}$ & $\begin{array}{l}\text { Group B } \\
(n=123)\end{array}$ & $\begin{array}{l}\text { Group C } \\
(n=90)\end{array}$ & $P$ value \\
\hline CDDP plus PEM & & & & \\
No. of patient $(\%)$ & $0(0 \%)$ & $38(30.9 \%)$ & $42(46.7 \%)$ & $0.007\left(\chi^{2}\right.$ test $)$ \\
$\begin{array}{c}\left.\text { Dosage (mg/m }{ }^{2}\right) \\
\text { CBDCA plus PEM }\end{array}$ & - & $73.2(71.9-74.0)$ & $73.3(72.4-74.4)$ & 0.64 (Mann-Whitney $U$ test) \\
No. of patient $(\%)$ & $7(87.5 \%)$ & $59(48.0 \%)$ & $31(34.4 \%)$ & $0.008\left(\chi^{2}\right.$ test $)$ \\
Target AUC & $4.68 \pm 1.23$ & $4.93 \pm 0.77$ & $5.15 \pm 0.80$ & 0.53 (one-way ANOVA) \\
Bev plus PEM & & & $8(8.9 \%)$ & $0.56\left(\chi^{2}\right.$ test) \\
No. of patient $(\%)$ & $0(0 \%)$ & $10(8.1 \%)$ & & \\
\hline
\end{tabular}

$P E M$ pemetrexed, $C D D P$ cisplatin, $C B D C A$ carboplatin, $A U C$ area under the concentration-time curve, $B e v$ bevacizumab

\section{Safety}

When assessing the onset of adverse events in each group by grade, the incidence of grade 1 thrombocytopaenia was higher in group B as compared to that in group $\mathrm{C}$, while for grade 2, the incidence was higher in group A as compared to that in groups B and C. No significant association of severe adverse events ( $\geq$ grade 3 ) with leucocyte, neutrophil and red blood cell counts, haemoglobin levels (Table 3) and elevated AST and ALT was observed between the three groups (Table 4).

\section{Risk factors}

We examined potential risk factors for thrombocytopaenia of $\geq$ grade 2 . Univariate analysis revealed a significant difference for the three following factors: CLcr of $<45 \mathrm{~mL} /$ min, CDDP administration and CBDCA administration. In contrast, for other factors such as age, PEM dosage and NSAIDs administration, no significant difference was observed. On multivariate analysis of the three factors that exhibited a significance level of $<20 \%$ on univariate analysis, only a CLcr of $<45 \mathrm{~mL} / \mathrm{min}$ was an independent risk factor. The administration of platinum-based preparations was not found to be a risk factor (Table 5). Among the eight patients with a CLcr of $<45 \mathrm{~mL} / \mathrm{min}$, none of the five patients who developed thrombocytopaenia of $\geq$ grade 2 exhibited a decrease in CLcr of $>10 \mathrm{~mL} / \mathrm{min}$ over that at the time of initiation of the second course of treatment.

\section{Discussion}

The safety of PEM-containing regimens in patients with a CLcr of $<45 \mathrm{~mL} / \mathrm{min}$ has yet to be established. In this study, administration of a PEM-containing regimen to patients with a CLcr of $<45 \mathrm{~mL} / \mathrm{min}$ was associated with a significantly higher incidence of thrombocytopaenia of $\geq$ grade 2 . Furthermore, the propensity of CBDCA to cause thrombocytopaenia is well known [27-29], and upon identification of risk factors for thrombocytopaenia of $\geq$ grade 2 , we found a CLcr of $<45 \mathrm{~mL} / \mathrm{min}$ to be an independent risk factor. In other words, CBDCA and other factors appeared to have had little effect. Moreover, although the dosage was low in group A, the onset of thrombocytopaenia of $\geq$ grade 2 appeared not to be affected by PEM dosage. This suggests that renal function is a stronger correlate of the onset of thrombocytopaenia in patients receiving PEM therapy. The incidence of other types of haematotoxicity (as evidenced by haematological results) and liver dysfunction also appeared to be unaffected by renal function.

On subgroup analysis, none of the patients with a CLcr of $<45 \mathrm{~mL} / \mathrm{min}$ who developed thrombocytopaenia of $\geq$ grade 2 showed a decrease in CLcr by $\geq 10 \mathrm{~mL} / \mathrm{min}$ by the start of the second course. This supports the notion that a further decline in renal function did not affect the incidence of thrombocytopaenia in the present study. Fall in platelet counts generally occurs 7-10 days after the initiation of anticancer therapy, and the period of platelet decrease is considered to be approximately 14 days. In the present study, the mean platelet nadir period was 13 days, which is consistent with earlier reports. Therefore, it may be inferred that the occurrence of thrombocytopaenia of $\geq$ grade 2 in patients with compromised renal function does not necessarily imply a specific mechanism, but only the incidence is increased.

Furthermore, in the present study, the incidence of haematotoxicity in patients with a CLcr of $<45 \mathrm{~mL} /$ min included neutropaenia of $\geq \operatorname{grade} 3(37.5 \%)$ and thrombocytopaenia of $\geq$ grade $3(12.5 \%)$. A breakdown of treatment methods revealed that PEM + CBDCA therapy was used in 7 out of 8 patients. This result was not remarkably higher than those reported by Schuette et al. [30] who evaluated PEM + CBDCA therapy 
Table 3 Incidence of haematotoxicity by grade and study group

\begin{tabular}{|c|c|c|c|c|}
\hline & $\begin{array}{l}\text { Group A } \\
(n=8)\end{array}$ & $\begin{array}{l}\text { Group B } \\
(n=123)\end{array}$ & $\begin{array}{c}\text { Group C } \\
(n=90)\end{array}$ & $\begin{array}{l}P \text { value } \\
\left(\chi^{2} \text { test }\right)\end{array}$ \\
\hline \multicolumn{5}{|c|}{ Leukopaenia } \\
\hline Grade 1 & $0(0 \%)$ & $10(8.1 \%)$ & $13(14.4 \%)$ & 0.219 \\
\hline Grade 2 & $2(25.0 \%)$ & $36(29.3 \%)$ & $19(21.1 \%)$ & 0.362 \\
\hline Grade 3 & $2(25.0 \%)$ & $15(12.2 \%)$ & $10(11.1 \%)$ & 0.510 \\
\hline Grade 4 & $0(0 \%)$ & $0(0 \%)$ & $2(2.2 \%)$ & 0.237 \\
\hline \multicolumn{5}{|c|}{ Neutropaenia } \\
\hline Grade 1 & $1(12.5 \%)$ & $21(17.1 \%)$ & $18(20.0 \%)$ & 0.816 \\
\hline Grade 2 & $2(25.0 \%)$ & $29(23.6 \%)$ & $21(23.3 \%)$ & 0.988 \\
\hline Grade 3 & $2(25.0 \%)$ & $18(14.6 \%)$ & $11(12.2 \%)$ & 0.567 \\
\hline Grade 4 & $1(12.5 \%)$ & $7(5.7 \%)$ & $5(5.6 \%)$ & 0.718 \\
\hline \multicolumn{5}{|l|}{ Anaemia } \\
\hline Grade 1 & $4(50.0 \%)$ & $71(57.7 \%)$ & $48(53.3 \%)$ & 0.831 \\
\hline Grade 2 & $1(12.5 \%)$ & $20(16.3 \%)$ & $20(22.2 \%)$ & 0.528 \\
\hline Grade 3 & $0(0 \%)$ & $5(4.1 \%)$ & $7(7.8 \%)$ & 0.409 \\
\hline Grade 4 & $0(0 \%)$ & $0(0 \%)$ & $0(0 \%)$ & - \\
\hline \multicolumn{5}{|c|}{ Thrombocytopaenia } \\
\hline Grade 1 & $3(37.5 \%)$ & $68(55.3 \%)$ & $35(38.9 \%)^{\mathrm{c}}$ & 0.037 \\
\hline Grade 2 & $4(50.0 \%)$ & $6(4.9 \%)^{\mathrm{a}}$ & $7(7.8 \%)^{\mathrm{b}}$ & $<0.001$ \\
\hline Grade 3 & $1(12.5 \%)$ & $8(6.5 \%)$ & $2(2.2 \%)$ & 0.214 \\
\hline Grade 4 & $0(0 \%)$ & $4(3.3 \%)$ & $3(3.3 \%)$ & 0.873 \\
\hline
\end{tabular}

$\chi^{2}$ test with Bonferroni correction

${ }^{\text {a }} P<0.01$ versus group $\mathrm{A}$

${ }^{\mathrm{b}} P<0.05$ versus group $\mathrm{A}$

c $P<0.05$ versus group B

(neutropaenia, $26.2 \%$; thrombocytopaenia, $16.9 \%$ ). Therefore, it is inferred that the incidence of haematotoxicity in patients with a CLcr of $<45 \mathrm{~mL} / \mathrm{min}$ was within the permissible range.
Table 4 Effect of chemotherapy on liver function

\begin{tabular}{llcll}
\hline & $\begin{array}{l}\text { Group A } \\
(n=8)\end{array}$ & $\begin{array}{l}\text { Group B } \\
(n=123)\end{array}$ & $\begin{array}{l}\text { Group C } \\
(n=90)\end{array}$ & $P$ value $\left(\chi^{2}\right.$ test $)$ \\
\hline AST increased & & & \\
Grade 1 & $3(37.5 \%)$ & $39(31.7 \%)$ & $35(38.9 \%)$ & 0.559 \\
Grade 2 & $0(0 \%)$ & $5(4.1 \%)$ & $4(4.4 \%)$ & 0.852 \\
Grade 3 & $0(0 \%)$ & $0(0 \%)$ & $1(1.1 \%)$ & 0.491 \\
Grade 4 & $0(0 \%)$ & $0(0 \%)$ & $0(0 \%)$ & - \\
ALT increased & & & \\
Grade 1 & $4(50.0 \%)$ & $67(54.5 \%)$ & $53(58.9 \%)$ & 0.702 \\
Grade 2 & $1(12.5 \%)$ & $4(3.3 \%)$ & $8(8.9 \%)$ & 0.172 \\
Grade 3 & $0(0 \%)$ & $4(3.3 \%)$ & $6(6.7 \%)$ & 0.423 \\
Grade 4 & $0(0 \%)$ & $0(0 \%)$ & $0(0 \%)$ & - \\
\hline
\end{tabular}

$A S T$ aspartate aminotransferase, $A L T$ alanine aminotransferase

With regard to patient background, a significant difference was observed between the groups in terms of age, type of chemotherapy regimen and use of NSAIDs. With regard to age, as groups were divided according to renal function, the fact that more elderly patients were included in groups $A$ and $B$ is consistent with earlier reports [31]. In group A, a CBDCA-combined regimen was most often used. In group C, a CDDP-combined regimen was most often used, which was assumed to be affected by the following facts: the CDDP dosage needs to be adjusted according to renal function [32] and because CDDP therapy has been found to cause renal dysfunction [33], it is difficult to use CDDP in patients who have pre-existing renal impairment prior to the start of chemotherapy. Moreover, multivariate analysis revealed that the three factors (age, type of chemotherapy regimen and use of NSAIDs) had little effect on the onset of thrombocytopaenia of $\geq$ grade 2 .
Table 5 Risk factors for thrombocytopaenia of $\geq$ grade 2

\begin{tabular}{|c|c|c|c|c|}
\hline & \multicolumn{2}{|l|}{ Univariate analysis } & \multicolumn{2}{|l|}{ Multivariate analysis } \\
\hline & Odds ratio $(95 \% \mathrm{CI})$ & $P$ value & Odds ratio $(95 \% \mathrm{CI})$ & $P$ value \\
\hline Age (years) & $1.02(0.98-1.06)$ & 0.26 & & \\
\hline Male & $1.01(0.47-2.21)$ & 0.97 & & \\
\hline CLcr $<45 \mathrm{~mL} / \mathrm{min}$ & $10.17(2.31-44.77)$ & 0.002 & $6.40(1.41-29.10)$ & 0.016 \\
\hline Metastasis or infiltration tumour & $1.54(0.75-3.18)$ & 0.24 & & \\
\hline CDDP & $0.25(0.09-0.67)$ & 0.006 & $0.56(0.15-2.08)$ & 0.39 \\
\hline CBDCA & $3.96(1.80-8.73)$ & 0.001 & $2.47(0.86-7.09)$ & 0.093 \\
\hline Bev & $0.29(0.04-2.27)$ & 0.24 & & \\
\hline Dosage of PEM $\left(\mathrm{mg} / \mathrm{m}^{2}\right)$ & $1.00(0.99-1.02)$ & 0.93 & & \\
\hline NSAIDs & $0.85(0.39-1.89)$ & 0.70 & & \\
\hline
\end{tabular}

Predictive ability of final model quantified using the Hosmer-Lemeshow statistical test for goodness of fit; $P=0.756$

$C I$ confidence interval, $C L c r$ creatinine clearance; $C D D P$ cisplatin, $C B D C A$ carboplatin, Bev bevacizumab, $P E M$ pemetrexed, NSAIDs non-steroidal anti-inflammatory drug 
Our results suggest the need for close monitoring of platelet counts in patients with a CLcr of $<45 \mathrm{~mL} / \mathrm{min}$ undergoing treatment with PEM-containing regimens.

The retrospective nature of this study is a key limitation. Assessment of non-haematotoxicities that could not be evaluated on the basis of laboratory results should be further studied. PEM therapy is not currently recommended in patients with a CLcr of $<45 \mathrm{~mL} / \mathrm{min}$ in Japan, which explains the small sample size of eight patients in group A. This is likely to have introduced a bias with respect to patient characteristics (Table 1). However, multivariate analysis ruled out all risk factors other than renal function. Therefore, we believe that the results of the present study are useful. Our results along with those of other retrospective studies may help to determine the optimal dosage levels for patients with compromised renal function and may help improve the safety profile of PEM-containing regimens.

Considering the fact that renal function declines with age [31], along with a relatively higher incidence of NSCLC in elderly patients aged $>70$ years [34], it is imperative to establish the safety of PEM-containing regimens for patients with renal dysfunction. When using PEMcontaining regimens in patients with renal dysfunction corresponding to a CLcr of $<45 \mathrm{~mL} / \mathrm{min}$, attention should be given to the potential onset of thrombocytopaenia.

Acknowledgments We would like to thank the participating patients for their contribution to this study.

\section{Compliance with ethical standards}

Conflict of interest The authors declare that they have no conflict of interest.

Ethical approval All procedures performed in this study involving human participants were in accordance with the ethical standards of the institutional and/or national research committee and with the 1964 Declaration of Helsinki and its later amendments or comparable ethical standards.

Open Access This article is distributed under the terms of the Creative Commons Attribution 4.0 International License (http://creativecommons.org/licenses/by/4.0/), which permits unrestricted use, distribution, and reproduction in any medium, provided you give appropriate credit to the original author(s) and the source, provide a link to the Creative Commons license, and indicate if changes were made.

\section{References}

1. Mitsudomi T, Morita S, Yatabe Y et al (2010) Gefitinib versus cisplatin plus docetaxel in patients with non-small-cell lung cancer harbouring mutations of the epidermal growth factor receptor (WJTOG3405): an open label, randomised phase 3 trial. Lancet Oncol 11:121-128. doi:10.1016/ S1470-2045(09)70364-X
2. Rosell R, Carcereny E, Gervais R et al (2012) Erlotinib versus standard chemotherapy as first-line treatment for European patients with advanced EGFR mutation-positive non-smallcell lung cancer (EURTAC): a multicentre, open-label, randomised phase 3 trial. Lancet Oncol 13:239-246. doi:10.1016/ S1470-2045(11)70393-X

3. Zhou C, Wu YL, Chen G et al (2011) Erlotinib versus chemotherapy as first-line treatment for patients with advanced EGFR mutation-positive non-small-cell lung cancer (OPTIMAL, CTONG-0802): a multicentre, open-label, randomised, phase 3 study. Lancet Oncol 12:735-742. doi:10.1016/ S1470-2045(11)70184-X

4. Wu YL, Zhou C, Hu CP et al (2014) Afatinib versus cisplatin plus gemcitabine for first-line treatment of Asian patients with advanced non-small-cell lung cancer harbouring EGFR mutations (LUX-Lung 6): an open-label, randomised phase 3 trial. Lancet Oncol 15:213-222. doi:10.1016/S1470-2045(13)70604-1

5. Sequist LV, Yang JC, Yamamoto N et al (2013) Phase III study of afatinib or cisplatin plus pemetrexed in patients with metastatic lung adenocarcinoma with EGFR mutations. J Clin Oncol 31:3327-3334

6. Shaw AT, Kim DW, Nakagawa K et al (2015) Crizotinib versus chemotherapy in advanced ALK-positive lung cancer. N Engl J Med 373:1582. doi:10.1056/NEJMoa1214886

7. Seto T, Kiura K, Nishio M et al (2013) CH5424802 (RO5424802) for patients with ALK-rearranged advanced nonsmall-cell lung cancer (AF-001JP study): a single-arm, openlabel, phase 1-2 study. Lancet Oncol 14:590-598. doi:10.1016/ S1470-2045(13)70142-6

8. National Comprehensive Cancer Network (NCCN) (2013) Clinical practice guidelines in oncology-non-small cell lung cancerversion 2. http://www.nccn.org/professionals/physician_gls/ PDF/antiemesis.pdf. Accessed 12 April 2015

9. Negoro S, Masuda N, Takada Y et al (2003) Randomised phase III trial of irinotecan combined with cisplatin for advanced nonsmall-cell lung cancer. Br J Cancer 88:335-341

10. Greco FA, Hainsworth JD (1997) Paclitaxel (1-hour infusion) plus carboplatin in the treatment of advanced non-small cell lung cancer: results of a multicenter phase II trial. Semin Oncol 24:S12-14-S12-17

11. Schiller JH, Harrington D, Belani CP et al (2002) Comparison of four chemotherapy regimens for advanced non-small-cell lung cancer. N Engl J Med 346:92-98

12. Ohe Y, Ohashi Y, Kubota K et al (2007) Randomized phase III study of cisplatin plus irinotecan versus carboplatin plus paclitaxel, cisplatin plus gemcitabine, and cisplatin plus vinorelbine for advanced non-small-cell lung cancer: Four-Arm Cooperative Study in Japan. Ann Oncol 18:317-323

13. Scagliotti GV, Parikh P, von Pawel J et al (2008) Phase III study comparing cisplatin plus gemcitabine with cisplatin plus pemetrexed in chemotherapy-naive patients with advanced-stage nonsmall-cell lung cancer. J Clin Oncol 26:3543-3551. doi:10.1200/ JCO.2007.15.0375

14. Mita AC, Sweeney CJ, Baker SD et al (2006) Phase I and pharmacokinetic study of pemetrexed administered every 3 weeks to advanced cancer patients with normal and impaired renal function. J Clin Oncol 24:552-562

15. Funaguchi N, Nakajima Y, Kaito D et al (2015) Analysis of pemetrexed monotherapy in advanced non-small cell lung cancer patients with impaired renal function. Gan To Kagaku Ryoho 42:705-708

16. Sakata Y, Iwamoto $\mathrm{Y}$, Abe K, Miyamori S, Inata J, Kanehara M, Hiraki K (2013) Analysis of risk factors for severe adverse events of chemotherapy with pemetrexed and comparison of adverse event occurrence according to renal function. Yakugaku Zasshi 133:1209-1213 
17. Paz-Ares L, de Marinis F, Dediu M et al (2012) Maintenance therapy with pemetrexed plus best supportive care versus placebo plus best supportive care after induction therapy with pemetrexed plus cisplatin for advanced non-squamous non-small-cell lung cancer (PARAMOUNT): a double-blind, phase 3, randomised controlled trial. Lancet Oncol 13:247-255. doi:10.1016/ S1470-2045(12)70063-3

18. Paz-Ares LG, de Marinis F, Dediu M et al (2013) PARAMOUNT: final overall survival results of the phase III study of maintenance pemetrexed versus placebo immediately after induction treatment with pemetrexed plus cisplatin for advanced nonsquamous non-small-cell lung cancer. J Clin Oncol 31:28952902. doi:10.1200/JCO.2012.47.1102

19. Calvert AH, Newell DR, Gumbrell LA et al (1989) Carboplatin dosage: prospective evaluation of a simple formula based on renal function. J Clin Oncol 7:1748-1756

20. Ando Y, Minami H, Saka H, Ando M, Sakai S, Shimokata K (1997) Adjustment of creatinine clearance improves accuracy of Calvert's formula for carboplatin dosing. Br J Cancer 76:1067-1071

21. Ando M, Minami H, Ando Y et al (2000) Multi institutional validation study of carboplatin dosing formula using adjusted serum creatinine level. Clin Cancer Res 6:4733-4738

22. Nakagawa K, Kudoh S, Matsui K et al (2006) A phase I study of pemetrexed (LY231514) supplemented with folate and vitamin B12 in Japanese patients with solid tumours. Br J Cancer 95:677-682

23. Vogelzang NJ, Rusthoven JJ, Symanowski J et al (2003) Phase III study of pemetrexed in combination with cisplatin versus cisplatin alone in patients with malignant pleural mesothelioma. $\mathrm{J}$ Clin Oncol 21:2636-2644

24. Niyikiza C, Baker SD, Seitz DE et al (2002) Homocysteine and methylmalonic acid: markers to predict and avoid toxicity from pemetrexed therapy. Mol Cancer Ther 1:545-552

25. Kono M, Sakata Y, Sugawara T et al (2014) Assessment of risk factors for adverse events due to pemetrexed in patients with reduced renal function. Gan To Kagaku Ryoho 41:2587-2590

26. Posada MM, Bacon JA, Schneck KB et al (2015) Prediction of renal transporter mediated drug-drug interactions for pemetrexed using physiologically based pharmacokinetic modeling. Drug Metab Dispos 43:325-334. doi:10.1124/dmd.114.059618

27. Kitagawa R, Katsumata N, Shibata T et al (2015) Paclitaxel plus carboplatin versus paclitaxel plus cisplatin in metastatic or recurrent cervical cancer: the open-label randomized phase III trial JCOG0505. J Clin Oncol 33:2129-2135. doi:10.1200/ JCO.2014.58.4391

28. Ozols RF, Bundy BN, Greer BE et al (2003) Phase III trial of carboplatin and paclitaxel compared with cisplatin and paclitaxel in patients with optimally resected stage III ovarian cancer: a Gynecologic Oncology Group study. J Clin Oncol 21:3194-3200

29. Rosell R, Gatzemeier U, Betticher DC et al (2002) Phase III randomised trial comparing paclitaxel/carboplatin with paclitaxel/ cisplatin in patients with advanced non-small-cell lung cancer: a cooperative multinational trial. Ann Oncol 13:1539-1549

30. Schuette WH, Gröschel A, Sebastian M et al (2013) A randomized phase II study of pemetrexed in combination with cisplatin or carboplatin as first-line therapy for patients with locally advanced or metastatic non-small-cell lung cancer. Clin Lung Cancer 14:215-223. doi:10.1016/j.cllc.2012.10.001

31. Rowe JW, Andres R, Tobin JD et al (1976) The effect of age on creatinine clearance in men: a cross-sectional and longitudinal study. J Gerontol 31:155-163

32. Aronoff GR, Bennett WM, Berns JS et al (2007) Drug prescribing in renal failure, 5th edn. American College of Physicians, Philadelphia

33. Daugaard G, Abildgaard U, Holstein-Rathlou NH, Bruunshuus I, Bucher D, Leyssac PP (1988) Renal tubular function in patients treated with high-dose cisplatin. Clin Pharmacol Ther 44:164-172

34. Matsuda A, Matsuda T, Shibata A, Katanoda K, Sobue T, Nishimoto H, Japan Cancer Surveillance Research Group (2014) Cancer incidence and incidence rates in Japan in 2008: a study of 25 population-based cancer registries for the monitoring of cancer incidence in Japan (MCIJ) project. Jpn J Clin Oncol 44:388-396. doi:10.1093/jjco/hyu003 